\title{
Hélène MICHON, Saint François de Sales. Une
} nouvelle mystique

Paris, Éditions du Cerf, coll. « Patrimoines-Christianisme », 2008, 353p.

\section{Daniel-Odon Hurel}

\section{CpenEdition}

Journals

Édition électronique

URL : http://journals.openedition.org/assr/21173

DOI : $10.4000 /$ assr.21173

ISSN : $1777-5825$

Éditeur

Éditions de l'EHESS

Édition imprimée

Date de publication : 31 décembre 2009

Pagination : $75-342$

ISBN : 978-2-7132-2218-4

ISSN : 0335-5985

Référence électronique

Daniel-Odon Hurel, « Hélène mıchon, Saint François de Sales. Une nouvelle mystique », Archives de sciences sociales des religions [En ligne], 148 | octobre-décembre 2009, document 148-94, mis en ligne le 03 juin 2009, consulté le 21 septembre 2020. URL : http://journals.openedition.org/assr/21173 ; DOI : https://doi.org/10.4000/assr.21173

Ce document a été généré automatiquement le 21 septembre 2020.

(C) Archives de sciences sociales des religions 


\title{
Hélène MICHON, Saint François de Sales. Une nouvelle mystique
}

Paris, Éditions du Cerf, coll. « Patrimoines-Christianisme », 2008, 353p.

\author{
Daniel-Odon Hurel
}

\section{RÉFÉRENCE}

Hélène Michon, Saint François de Sales. Une nouvelle mystique, Paris, Éditions du Cerf, coll. « Patrimoines-Christianisme », 2008, 353p.

1 L'image de François de Sales, le promoteur d'une spiritualité adressée aux laïcs, s'illustre-t-elle aussi à travers le Traité de l'amour de Dieu, qui serait en quelque sorte la transposition dans une langue simple et vernaculaire, des mystères de la science théologique et mystique ? Ce livre constitue une analyse complète de ce texte essentiel de l'histoire de la spiritualité et de la mystique du xvII siècle, ouvrage dans lequel les concepts théologiques sont présents mais aussi une expérience de l'ascension mystique, insérée ainsi dans le cadre théologique et scripturaire et au cœur de l'Église.

2 Hélène Michon s'attache d'abord à étudier la théologie mystique de François de Sales, en l'insérant dans son histoire, des origines dionysiennes à Bérulle, montrant les modalités du recours au texte biblique, mettant en valeur l'absence d'opposition entre dévotion et "mystique ", mot signifiant d'abord l'union affective en elle-même et non le «sommet» de cette union. Parallèlement, le Traité de l'amour de Dieu définit une anthropologie fondée sur la connaissance de soi qui permet une inclination de l'homme vers Dieu et qui renvoie à la structure de l'âme, point de départ pour aller à Dieu grâce au dynamisme de la volonté et au bon usage des passions. L'analyse des modalités de l'ascension vers Dieu permet à l'auteure d'analyser les diverses influences à l'origine de l'œuvre de François de Sales: Thérèse d'Avila, Benoît de Canfeld et Bernard de Clairvaux. Si François de Sales se situe dans la spiritualité du pur amour, il maintient l'activité du sujet tout en accentuant le nécessaire abandon de la volonté propre. 
3 Dans une dernière partie, H. Michon expose la synthèse salésienne : une théologie et une spiritualité accessibles, dans laquelle la providence, le mystère de la grâce et les vertus constituent le socle d'une montée vers Dieu qui ne peut prendre place hors de l'Église. À travers cette étude, la modernité de la mystique salésienne apparaît comme la complémentarité entre l'héritage de la tradition chrétienne et la modernité tridentine. Il s'agit pour François de Sales de manifester une vraie préoccupation à l'égard de la formation et de la vis spirituelle de tous les chrétiens, qu'ils soient religieux et religieuses, prêtres et surtout laïcs. S'inscrivant dans l'Église, l'évêque refuse de séparer théologie et mystique, de séparer le dogme de l'expérience et affirme la force de l'union entre expérience ecclésiale et expérience individuelle. François de Sales est enfin moderne car il est aussi acteur et spectateur de la spiritualité moderne, celle qui donne une place à l'exigence d'une relation personnelle à Dieu dans la vie chrétienne, quel que soit son état. 